University of Nebraska - Lincoln

DigitalCommons@University of Nebraska - Lincoln

Faculty Publications: Agricultural Leadership, Education \& Communication Department
Agricultural Leadership, Education \& Communication Department

April 2004

\title{
IDENTIFYING SOURCES OF MOTIVATION OF ADULT RURAL WORKERS
}

John E. Barbuto Jr.

University of Nebraska - Lincoln, jbarbuto@unInotes.unl.edu

Shirley K. Trout

University of Nebraska - Lincoln

Lance L. Brown

University of Nebraska - Lincoln

Follow this and additional works at: https://digitalcommons.unl.edu/aglecfacpub

Part of the Other Public Affairs, Public Policy and Public Administration Commons

Barbuto, John E. Jr.; Trout, Shirley K.; and Brown, Lance L., "IDENTIFYING SOURCES OF MOTIVATION OF ADULT RURAL WORKERS" (2004). Faculty Publications: Agricultural Leadership, Education \& Communication Department. 5.

https://digitalcommons.unl.edu/aglecfacpub/5

This Article is brought to you for free and open access by the Agricultural Leadership, Education \& Communication Department at DigitalCommons@University of Nebraska - Lincoln. It has been accepted for inclusion in Faculty Publications: Agricultural Leadership, Education \& Communication Department by an authorized administrator of DigitalCommons@University of Nebraska - Lincoln. 


\title{
IDENTIFYING SOURCES OF MOTIVATION OF ADULT RURAL WORKERS
}

\author{
John E. Barbuto, Jr., Associate Professor of Leadership \\ Shirley K. Trout, Doctoral Candidate in Leadership Studies \\ Lance L. Brown, Extension Educator \\ University of Nebraska-Lincoln
}

\begin{abstract}
A meta-theory of motivation is described and used to establish norms among farm cooperative employees and managers in Nebraska. One hundred eighty six farm cooperative employees and managers were administered the Motivation Sources Inventory (MSI) and the five sources of work motivation-intrinsic process, instrumental, self-concept external, self-concept internal, and goal internalization-were examined. Results demonstrate a high proportion of self-concept internal work motivation among rural workers. The other four sources were evenly distributed across the sample population. This baseline study implies that employers, supervisors and educators may engage the interest and involvement of rural workers most effectively when they incorporate influence attempts that appeal to workers' internally derived standards and sense of the ideal self. Limitations and further implications for education, practice and future research are discussed.
\end{abstract}

\section{Introduction}

Leader and follower motivation has important implications for selection, promotion, design, implementation and evaluation of education and development activities (Dollisso \& Martin, 1999). Agricultural educators have long felt an apparent uniqueness in the motivation of their target audiences (Swanson, 1984), yet the lack of psychometric measures has hindered the field's understanding of these motives. Several scholars have begun examining the motives or drives of individuals in rural community settings (Bajema, Miller \& Williams, 2002; Culp, 1997; Fritz, Barbuto, Marx, Etling, \& Burrow, 2000). Motivation appears to be salient to agricultural educators and rural community leaders. This study introduces to the agricultural education field a psychometric tool that can be used to accurately assess motivations of agricultural audiences.

Motivation has been examined from many perspectives, yet arguments over the merits of each viewpoint have been long and exhaustive in the social sciences literature
(Higgins \& Kruglanski, 2000; Pittman, 1998). The results of such efforts have generally fallen short of providing an integrative framework (Barbuto, 2001a). Leonard, Beauvais, and Scholl (1999) proposed an integrative model of motivation built on research efforts in the field. In their model, several theorists' perspectives were integrated, identifying five sources of motivation. These sources included intrinsic process, instrumental, external and internal self-concept, and goal internalization.

The meta-theory of motivation was operationalized by Barbuto and Scholl (1998) with the development and validation of the 30-item Motivation Sources Inventory (MSI). Use of the inventory has demonstrated strong relations with influence tactics (Barbuto \& Scholl, 1999) and transformational behaviors (Barbuto, Fritz \& Marx, 2000). Other correlations have been found in applied research with immigrant students' adjustment (Tsytsarev \& Lantsman, 1999), and organizational citizenship and altruistic behaviors (Barbuto, Brown, Wheeler, \& Wilhite, 2003).

The Motivation Sources Inventory was used in this study to identify motivation 
sources of agriculture cooperative employees and rural managers. Findings have implications for identifying, marketing and adapting appropriate employment and developmental activities relevant to this population. It also can provide opportunities to compare motivation sources of agricultural populations, which may have important implications for educators and policymakers.

\section{Research in Sources of Motivation}

Motivation has been examined from many perspectives, including psychosocial (Jung, 1971) need-based (Maslow, 1954; McClelland, 1961), intrinsic (Deci, 1975; Katz \& Kahn, 1978), social identity (Ashforth \& Mael, 1989), value-based (Etzioni, 1961; Kelman, 1958), goal setting (Locke \& Latham, 1984), self concept-based (Brief \& Aldag, 1981; Gecas, 1982; Snyder \& Williams, 1982; Sullivan, 1989), and to some extent, developmental (Kegan, 1982; Kohlberg, 1976; Loevinger, 1976) perspectives. Arguments over the merits of each viewpoint have been long and exhaustive in the social sciences literature. The results of such efforts have generally fallen short of providing an integrative framework.

Perhaps the most accepted and applied taxonomy of motivation is the trichotomy developed and operationalized by McClelland (1961, 1987). This theory of motivation emphasized three needs - need for power, need for affiliation, and need for achievement. Despite its general acceptance, the trichotomy and its measure, the Thematic Apperception Test (TAT) have been criticized (Barbuto \& Scholl, 1998). Recently, a new typology of motivation sources was proposed by Leonard, Beauvais, and Scholl (1999) and was later operationalized with scales to measure the taxonomy (Barbuto \& Scholl, 1998). This typology was further developed and tested to predict leaders' behaviors (Barbuto \& Scholl, 1999; Barbuto, et al., 2000). The five sources of motivation measured include intrinsic process, instrumental, self-concept-external, self-concept-internal, and goal internalization. A brief description of these five sources of motivation follows. Table 1 provides a comparison of major theorists from which this taxonomy was derived.

\section{Intrinsic Process Motivation}

If a person is motivated to perform certain kinds of work or to engage in certain types of behavior for the sheer fun of it, then intrinsic process motivation is taking place. In this source of motivation, the work itself acts as the incentive. Similar constructs to intrinsic process motivation can be found in the literature. Need-based descriptions similar to intrinsic process include early existence needs (Alderfer, 1969), intrinsic pleasure needs (Murray, 1964) and physiological needs (Maslow, 1954). Bandura (1986) describes sensory intrinsic motivation in terms similar to those used to describe intrinsic process motivation.

The term intrinsic motivation is often used to represent personal satisfaction derived from achievement of goals or tasks. Intrinsic process, as used here, is distinct from the classical interpretation of intrinsic motivation by its emphasis on immediate enjoyment or pleasure during the activity, rather than on the satisfaction that results from its achievement. The classic intrinsic motivation is represented in this motivation taxonomy as self-concept internal (Barbuto \& Scholl, 1998).

\section{Instrumental Motivation}

Instrumental rewards motivate individuals when they perceive their behavior will lead to certain tangible outcomes, such as pay, promotions, bonuses, etc. This source of motivation integrates Barnard's (1938) exchange theory, and Katz and Kahn's (1978) legal compliance and external rewards. Developmental theorists described a similar stage as concrete operational (Piaget, 1972), instrumental (Kohlberg, 1976), and imperial (Kegan, 1982). Similar instrumental motives have been described as a need for power (Murray, 1964; McClelland, 1961), a need for safety (Maslow, 1954), later stages of existence needs (Alderfer, 1969), extrinsic motivation (Staw, 1976; Deci, 1975; Bandura, 1986), and material inducements (Barnard, 1938). 


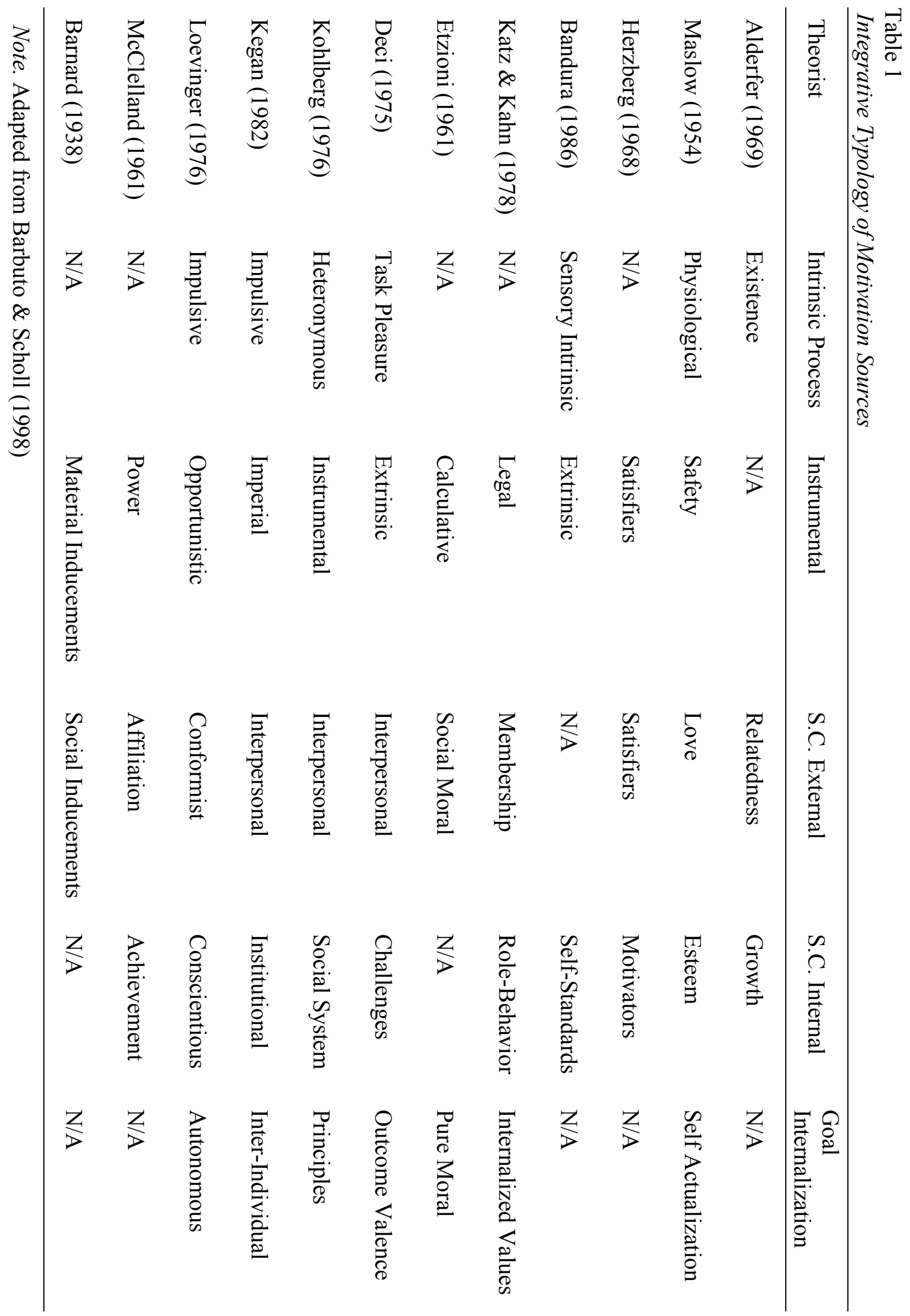


Instrumental motivation is different from the classic extrinsic or external motivation in that this motive derives from tangible external rewards, whereas the classic definition includes social rewards and interpersonal relations (termed "selfconcept-external" in this typology). The instrumental motive, calculative in nature, is likely to pursue the most personally advantageous outcome. Individuals motivated by instrumental motives are more likely to seek the optimum balance of inputs and outputs (Barbuto \& Scholl, 1998).

\section{Self-Concept-External Motivation}

This source of motivation tends to be externally based when the individual is primarily other-directed and seeking affirmation of traits, competencies, and values. The individual behaves in ways that satisfy reference group members, first to gain acceptance, and then to gain status. This source of motivation also resembles social identity theory, where the focus is on establishing and maintaining social reference and standing (Ashforth \& Mael, 1989). Developmental theorists have discussed a similar motivational stage as interpersonal (Kohlberg, 1976; Kegan, 1982), early formal operational (Piaget, 1972), and conformist (Loevinger, 1976). Other researchers have described similar motivation as need for affiliation (McClelland, 1961; Murray, 1964), need for love, affection, and belonging (Maslow, 1954), and relatedness needs (Alderfer, 1969). Social rewards and peer comparisons are inherent in self-concept-external.

\section{Self Concept Internal Motivation}

This source of motivation is internally based when the individual is inner-directed. In this type of motivation, the individual sets internal standards of traits, competencies, and values that become the basis for the ideal self (Leonard, et al., 1999). The person is then motivated to engage in behaviors that reinforce these standards and later achieve higher levels of competency. This source is similar to McClelland's (1961) high need for achievement, Deci's (1975) internal motivation to overcome challenges, and Katz and Kahn's (1978) ideal of internalized motivation derived from role performance.
Developmental theorists have described a similar stage as full formal operational (Piaget, 1972), social system (Kohlberg, 1976), and institutional (Kegan, 1982). Similar motives are described as a need for achievement (McClelland, 1961; Murray, 1964), need for esteem (Maslow, 1954), and motivating factors (Herzberg, 1968). Bandura (1986) describes self-regulation and personal standards in terms similar to those used to describe internal self-concept. This motive also has been described as intrinsic motivation to overcome challenges (Deci, 1975) and intrinsic motivation to pursue personal achievement (Staw, 1976).

\section{Goal Internalization Motivation}

Behavior motivated by goal internalization occurs when the individual adopts attitudes and behaviors because their content is congruent with the individual's personal value system. Strong ideals and beliefs are paramount in this motivational source (Barbuto \& Scholl, 1998). The worker believes in the cause, has developed a strong sense of duty and is therefore motivated to work toward the goal of the collective. This source of motivation is similar to Katz and Kahn's (1978) internalized values, and Etzioni's (1961) pure moral involvement. Each of these perspectives emphasizes a virtuous character and a desire to not compromise these virtues. Developmental theorists describe a similar motivational stage as post-formal operational (Piaget, 1972), principled orientation (Kohlberg, 1976), and inter-individual (Kegan, 1982). Need theorists describe a similar motive as self-actualization (Maslow, 1954). Goal internalization is different from the previous four sources of motivation because it features the removal of self-interest (Barbuto \& Scholl, 1998). Motivation from this source occurs because individuals believe in the cause.

In summary, with intrinsic process motivation, the work itself acts as the incentive, as workers enjoy what they are doing. With instrumental motivation, rewards, such as pay, promotion, bonuses, etc., motivate the individual. With self-concept-external motivation, one's reputation or the way he or she is perceived 
by others is the motivating factor. With self-concept-internal motivation, an individual sets internal standards of traits, competencies, and values of an ideal self. The attainment of the ideal self serves as the motivation for behavior. With goal internalization, however, individuals do not require any strong inducements beyond a belief that the goals of the organization can be attained with their assistance. Persons motivated by goal internalization are motivated to work toward the goal of the collective. The taxonomy developed provides a much-needed framework for understanding individual behaviors and decision-making (Barbuto, 2000).

\section{Motivation in Rural and Agricultural Populations}

Several studies have sampled rural and/or agricultural populations and examined motivation using other conceptual frameworks and measures. For example, Culp (1997) examined positive and negative motivations of adult $4-\mathrm{H}$ volunteers. This study revealed three motives: youth, the 4-H program, and perceived need. Two negative motivators, also identified, were lack of assistance and a lack of time and employment conflicts. Turner and Herren (1997) examined the motivational needs of students using McClelland's (1961) three needs: power, affiliation, and achievement. Results suggested that agricultural students were motivated by need for achievement, and FFA members had stronger motivational needs across the trichotomy than non-FFA members. Their study found that students who lived on a farm had higher need for power than students living in an urban setting, and that Caucasians had a higher need for affiliation.

Dollisso and Martin (1999) studied young farmers regarding motivation to participate in educational programs. The key motives identified in this study were desire to increase profitability, desire to learn the latest technology, relevant material, and accessibility of the educational programs. Preferences also showed farmers identifying with more hands-on activities and through trial and error - suggesting that farmers require more immediate practical utility to warrant participation. Fritz, et al. (2000) studied the motivation and recognition preferences of $4-\mathrm{H}$ volunteers and found that on average, using McClelland's framework, volunteers were motivated by affiliation, and therefore embraced the social ties and connectedness embedded in 4- $\mathrm{H}$ volunteer activities. Volunteers also preferred to be recognized in a variety of ways.

Some trends from prior research with similar populations led to several expectations. Since rural students reported higher needs for power (Turner \& Herren, 1997) and farmers reported greater need for profitability and immediate utility (Dollisso \& Martin, 1999), it is reasonable to assume that instrumental and intrinsic process motivation may be prevalent with this population. However, since the entirety of this sample is cooperative managers and employees, not necessarily living on a farm, they likely embrace a mixture of farm and urban characteristics. Both Culp (1997) and Fritz, et al. (2000) found strong occurrence of McClelland's need for affiliation among 4-H volunteers. An argument could be made that similar results may be found with this population, where self-concept external may prevail. However, since the present population was not selected within the volunteerism context, but from paid employees, the potential similarities of samples and corresponding results were not expected. An opportunity exists for inquiry into the motivational profile of the agricultural worker. Other studies examining motivation have sampled volunteer 4-H leaders (Culp, 1997; Fritz, et al., 2000), agricultural adult learners (Dollisso \& Martin, 1999), and high school students (Turner \& Herren, 1997). To date, no studies have examined the motives of agricultural workers in business settings. This work represents the seminal examination of motivation for this population group.

\section{Purpose of the Study}

The purpose of this study was to test the Motivation Sources Inventory (MSI) in a 
population of agricultural workers. Specific objectives of this study were to:

1. Assess the reliability of the MSI for an agricultural business population.

2. Assess the relative predominance of each of the five sources of motivation in this population.

3. Establish population norms for practical implications.

\section{Methods and Procedures}

\section{Population and Sample}

Because the MSI had never been tested with agricultural workers, this population was considered an important target for testing the general validity of the instrument. Data for this analysis were collected from two farmer cooperatives located in the Midwestern United States. All of the possible 31 branch offices were included in the study, totaling a possible 245 employees and 40 of their managers and general managers. Of these, 168 completed the Motivation Sources Inventory (86\%). Eighty percent of the participants in this study were male.

\section{Measures}

The MSI (Barbuto \& Scholl, 1998) was used to measure the five sources of motivation. This instrument was developed to measure motivation in traditional business/organizational settings and has been used to predict leader influence tactics (Barbuto \& Scholl, 1999), transformational leadership behaviors (Barbuto, et al., 2000), organizational citizenship behaviors (Barbuto, Brown, Wheeler, \& Wilhite, 2003) and in a framework for understanding follower compliance (Barbuto, 2000). It has shown to be both reliable and valid, producing coefficient $\alpha$ of .60 to .93 (Barbuto \& Scholl, 1998; Barbuto \& Scholl, 1999; Barbuto et al., 2000) in a wide range of populations, (i.e., urban business, health care and social service workers, education professionals and college students). In this research, internal reliabilities of the five subscales were similar to previous studies, ranging here from .69 to .81 (Table 2).

\section{Procedures}

Participants volunteered to participate in the study and were rewarded with a professional interpretation of their motivation results. Cooperative employees received the MSI from their managers and returned the completed instrument directly to the researchers via U.S. Mail. Since some of these scores were to be used by the participating cooperatives for the enhancement of their leadership development programs, an $86.1 \%$ response rate was achieved. This high response rate is characteristic of intact groups for field studies (Barbuto, Fritz, \& Marx, 2000; Barbuto \& Scholl, 1999).

Participation in the research was voluntary. Participants had the option to withdraw from the study at anytime during the process, even after data was collected. No participant asked to be removed from the study. Confidentiality was assured by having all completed instruments returned to the first author. No representatives/employees in the organizations had access to any of the information provided; however individuals were provided their individual results.

\section{Analysis and Results}

The first objective of this study was to assess the reliability of the MSI for an agricultural business population. The normal distribution obtained during the analysis combined with the strong internal reliability estimates of each of the five subscales supported the reliability of the instrument for use with this population.

The second objective was to assess the relative predominance of each of the five sources of motivation in this population. Analysis of the MSI included parceling the 30 motivation items into five subscales. Barbuto (2001b) advocated ratio analysis for better capturing the proportion with which motivation sources exist. This procedure alleviates some of the inherent response bias associated with self-report Likert-type scales, 
such as was used in the MSI (Table 2 and Figure 1).

Results of this study indicate that the most prevalent source of motivation was the self-concept internal. This implies that agricultural workers are inner-directed and operate according to their own belief of what they consider to be their ideal self. Persons proportionately high in self-concept internal are likely to be motivated by inducements that reinforce their personal standards and allow them to achieve higher levels of competence. They get value out of doing their jobs well - according to their own standards - and do not rely heavily on external inducements in order to perform tasks to a high standard. This is not to suggest that they don't require reinforcement and recognition for good work, but self-concept internal implies a natural motivation to live up to a personal standard. The remaining four motives were distributed across the agricultural business population without pattern.

Table 2

Rural Adults' Motivations: Summary of Data Results

\begin{tabular}{lcccccc}
\hline MSI Subscales & $N$ & $M$ & $S D$ & Ratio & Ratio $(S D)$ & Coefficient $(\alpha)$ \\
\hline 1. Intrinsic Process & 186 & 19.32 & 5.49 & .187 & .036 & .74 \\
2. Instrumental & 186 & 19.18 & 5.31 & .187 & .038 & .70 \\
3. Self-Concept External & 186 & 16.74 & 5.87 & .167 & .043 & .71 \\
4. Self-Concept Internal & 186 & 28.03 & 4.17 & .281 & .057 & .81 \\
5. Goal Internalization & 186 & 19.27 & 5.14 & .184 & .184 & .69
\end{tabular}

${ }^{1}$ Calculated by dividing the mean reported source of motivation by the total population reported for means of all five sources of motivation. Example: intrinsic process ratio $=[19.32 /$ $(19.32+19.18+16.74+28.03+19.27)]=.187$

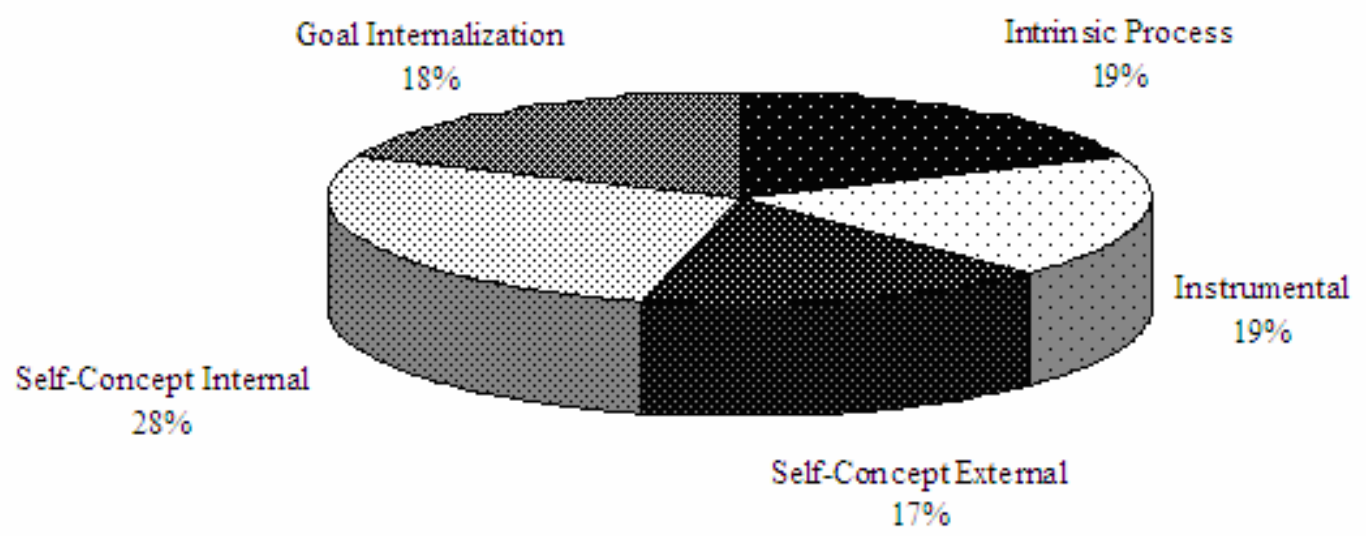

Figure 1. Agricultural Cooperative Employee's Ratio Analysis of Motivation Sources 
The final objective for this study was to establish norms for the agricultural worker population. Findings indicate that this agricultural population is proportionately more motivated by self-concept internal than by other motivation sources. These results provide a reasonable initial indication that selfconcept internal is the prevailing motivation source among agricultural workers. Based on these findings, employers and managers of agricultural workers are encouraged to become familiar with specific activities and inducements that resonate within their staff based on this motivation source. Educators may use these results to employ appropriate recruitment strategies as they target agricultural business workers for participation in extension and other educational programs.

\section{Conclusions and Future Research Opportunities}

This study provides evidence that the Motivation Sources Inventory is a reliable instrument to measure motivation in agricultural workers, demonstrating reliability consistent with its use in other populations (Barbuto, Fritz \& Marx, 2000; Barbuto \& Scholl, 1999). Results indicated that self-concept internal motivation was the highest motivation source in agricultural workers. This means that personal standards represent over $28 \%$ of an individual's total motivation pattern for this population.

These results provide a population norm against which future studies can be compared. Findings of this study will be of interest to employers, managers and organizational leaders who make decisions about how best to motivate employees or followers to comply with instructions or engage in other organizational goals. The high proportion of self-concept internal found in this study indicated that agricultural workers need more than just a pleasant work environment, higher pay, public recognition or a worthy cause to give their greatest effort. While these should not be discarded as non-essential considerations, the greater appeal will be that which strikes a chord with the individual's internal standard of traits, competencies, and values as they impact the self-determined ideal self. Only by getting to know the unique nature of these traits, competencies and values will an employer, manager or other leader have the greatest probability for successfully motivating agricultural workers.

There are several opportunities for future research that can add value to this work. Expanding the sample size in a similar research design will strengthen the generalization of norms. Designing studies that will compare matched agricultural and non-agricultural populations will help agricultural educators, community development professionals and others better understand how programming and appeal strategies might differ among these audiences.

The motivation taxonomy may effectively explain behaviors at multiple levels of organizations (followers, peers, etc.). Additional research should explore differences in motivation among rural populations, such as gender, adoption of production practices, purchasing behaviors and participation in educational opportunities. To best serve outcome assessment, further research should integrate motivation sources into comparisons of program evaluations between agricultural and non-agricultural populations.

\section{Implications for Practice}

Based on these findings, supervisors, managers and other leaders are encouraged to learn about goals and standards of employees and followers, discover what they consider important, and create a work environment that encourages and supports workers' standards of achievement. Beyond the work environment, this study strengthens the work of Turner and Herren (1997), which found that agricultural education students were motivated by need for achievement. Identifying specific motivation sources of target audiences can help agricultural educators better understand how to select, design, promote, deliver and evaluate programs. If further research continues to identify a consistent pattern of high self-concept internal motivation, this will influence how to position certain 
programming to attract the greatest participation from ag workers. For example, marketing and program delivery for this target population may need to focus more attention on individuals' internal standards and values (e.g., high-quality work, flexible working environment, diverse task assignments, autonomy).

In addition, by comparing differences in motivation sources among and between target audiences, educators can potentially adapt program content and marketing approaches, thus increasing participation rates and the adoption, integration or application of desired outcomes. This study provides a valuable contribution by introducing an instrument that can strengthen the empirical study of motivation in agricultural populations and by establishing a relevant-population norm.

The adage that people are motivated by money was definitively refuted by the findings of this work. In the agricultural setting, money, operationalized as instrumental motivation, provides no more inducement than fun (intrinsic process), reputation (self-concept external), or purpose (goal internalization). The relative proportion of self-concept internal found in this ratio analysis leads the scholar-practitioner to rethink old assumptions about human motivation. It imparts the need to tap into the self-concept internal motives of agricultural workers (Barbuto \& Brown, 2001). Proactive and sustained efforts to tap this source of motivation will increase the likelihood of inducing motivated work or participation in educational programming for this population.

\section{References}

Alderfer, C. P. (1969). An empirical test of a new theory of human needs. Organizational Behavior and Human Performance, 4, 142-175.

Ashforth, B., \& Mael, F. (1989). Social identity theory and the organization. Academy of Management Review, 14, 20-39.

Bajema, D. H., Miller, W. W., \&
Williams, D. L. (2002). Aspirations of rural youth. Journal of Agricultural Education, 43(3), 61-71.

Bandura, A. (1986). Social foundations of thought and action: A social cognitive theory. Englewood Cliffs, NJ: Prentice Hall.

Barbuto, J. E. (2000). Influence triggers: A framework for understanding follower compliance. Leadership Quarterly, 11(3), 365-387.

Barbuto, J. E. (2001a). Understanding and applying an integrative taxonomy of motivation sources to professional and personal settings. Journal of Management Education, 25, 713-725.

Barbuto, J. E. (2001b). An alternative scoring method for the motivation sources inventory: A case for ratio analysis. Psychological Reports, 88, 385-386.

Barbuto, J. E., \& Brown, L. L. (2001). 77 ways to motivate workers (NebGuide G01-1440-A). Lincoln, NE: Cooperative Extension, University of Nebraska-Lincoln.

Barbuto, J. E., Brown, L. L., Wheeler, D. W., \& Wilhite, M. S. (2003). Motivation, altruism, and generalized compliance: A field study of organizational citizenship behaviors. Psychological Reports, 92, 498502.

Barbuto, J. E., Fritz, S. M., \& Marx, D. (2000). A field study of two measures of work motivation for predicting leaders' transformational behaviors. Psychological Reports, 86, 295-300.

Barbuto, J. E., \& Scholl, R. W. (1998). Motivation Sources Inventory: Development and validation of new scales to measure an integrative taxonomy of motivation. Psychological Reports, 82, 1011-1022.

Barbuto, J. E., \& Scholl, R. W. (1999). Leader's sources of motivation and perceptions of follower's motivation as predictors of leader's influence tactics used. Psychological Reports, 84, 1087-1098. 
Barnard, C. (1938). The functions of the executive. Cambridge, MA: Harvard Press.

Brief, A., \& Aldag, R. (1981). The self in organizations: A conceptual review. Academy of Management Review, 6, $75-88$.

Culp, III., K. (1997). Motivating and retaining adult volunteer 4-H leaders. Journal of Agricultural Education, 38(2), 1-7.

Deci, E. L. (1975). Intrinsic motivation. New York: Plenum Press.

Dollisso, A. D., \& Martin, R. A. (1999). Perceptions regarding adult learners motivation to participate in educational programs. Journal of Agricultural Education, 4(4), 38-46.

Etzioni, A. (1961). A comparative analysis of complex organizations. Glencoe, IL: Free Press.

Fritz, S., Barbuto, J. E., Marx, D., Etling, A., \& Burrow, S. (2000). Motivation and recognition preferences of 4-H volunteers. Journal of Agricultural Education, 41(3), 40-49.

Gecas, V. (1982). The self concept. Annual Review of Sociology, 8, 1-33.

Herzberg, F. W. (1968). One more time, how do you motivate employees? Harvard Business Review, Jan.-Feb., 53-62.

Higgins, E. T. \& Kruglanski, A. W. (2000). Motivational science: The nature and functions of wanting. In Higgins, E. T. \& Kruglanski, A. W. (Eds.). Motivational science: Social and personality perspectives, 1-20. Philadelphia, PA: Psychology Press.

Jung, C. G. (1971). Psychological types. Princeton, NJ: Princeton University Press.

Katz, D., \& Kahn, R. L. (1978). The social psychology of organizations. NY: Wiley.
Kegan, R. (1982). The evolving self. Cambridge, MA: Harvard University Press.

Kelman, H. C. (1958). Compliance, identification, and internalization: Three processes of attitude change. Journal of Conflict Resolution, 2, 51-56.

Kohlberg, L. (1976). Collected papers on moral development and moral education. Cambridge, MA: Center for Moral Education.

Leonard, N. H., Beauvais, L. L., Scholl, R. W. (1999). Work motivation: The incorporation of self-concept-based processes. Human Relations, 52, 969-998.

Locke, E., \& Latham, G. (1984). Goal setting: A motivational technique that works. Englewood Cliffs, NJ: Prentice Hall.

Loevinger, J. (1976). Ego development. San Francisco: Jossey-Bass, Inc.

Maslow, A. (1954). Motivation and personality. New York: Harper \& Row.

McClelland, D. C. (1961). The achieving society. Princeton, NJ: Van Nostrand.

McClelland, D. C. (1987). Human motivation. Cambridge, NY: Cambridge University Press.

Murray, E. J. (1964). Motivation and emotion. Englewood Cliffs, NJ: PrenticeHall.

Piaget, J. (1972). Intellectual evolution from adolescence to adulthood. Human Development, 15, 1-12.

Pittman, T. S. (1998). Motivation. In D. T. Gilbert, S. T. Fiske, \& G. Lindzey (Eds.), Handbook of social psychology, 1, 549-590. New York: McGraw-Hill.

Snyder, R., \& Williams, R. (1982). Self theory: An integrative theory of work motivation. Journal of Occupational Psychology, 55, 257-267. 
Staw, B. M. (1976). Intrinsic and extrinsic motivation. Morristown, NJ: Silver Burdett.

Sullivan, J. (1989). Self theories and employee motivation. Journal of Management, 15, 345-363.

Swanson, B. E. (Ed.) (1984). Agricultural extension: A reference manual. Rome: Food and Agriculture Organization of the United Nations.
Tsytsarev, S., \& Lantsman, M. (1999). Acculturation and academic success of young Russian-speaking college students. Unpublished thesis, Hofstra University.

Turner, J., \& Herren, R. V. (1997). Motivational needs of students enrolled in Agricultural Education programs in Georgia. Journal of Agricultural Education, 38(4), 30-41.

JOHN E. BARBUTO, JR. is an Associate Professor of Leadership in the Department of Agricultural Leadership, Education and Communication at the University of Nebraska-Lincoln, 300 Ag Hall, Lincoln, NE 68583-0709. E-mail: jbarbuto@unl.edu.

SHIRLEY K. TROUT is a Doctoral Candidate in Leadership Studies in the Department of Agricultural Leadership, Education and Communication at the University of Nebraska-Lincoln, 300 Ag Hall, Lincoln, NE 68583-0709. E-mail: strout2@,unl.edu.

LANCE L. BROWN is an Extension Educator in the Department of Agricultural Leadership, Education and Communication at the University of Nebraska-Lincoln, $300 \mathrm{Ag}$ Hall, Lincoln, NE 68503-4947. E-mail: Lbrown4@unl.edu. 